\title{
Expression of NDRG2 is related to tumor progression and survival of gastric cancer patients through Fas-mediated cell death
}

\author{
Seung-Chul Choi ${ }^{1 *}$, Suk Ran Yoon ${ }^{1 *}$, \\ Yuk Pheel Park', Eun Young Song ${ }^{1}$, Jae Wha Kim ${ }^{1}$, \\ Woo Ho Kim², Young Yang ${ }^{3}$, Jong-Seok Lim ${ }^{3}$ \\ and Hee Gu Lee ${ }^{1,4}$ \\ ${ }^{1}$ Stem Cell Research Center \\ Korea Research Institute of Bioscience and Biotechnology \\ Daejeon 305-608, Korea \\ ${ }^{2}$ Department of Pathology \\ Seoul National University College of Medicine \\ Seoul 110-799, Korea \\ ${ }^{3}$ Department of Biological Sciences and \\ the Research Center for Women's Diseases \\ Sookmyung Women's University \\ Seoul 140-742, Korea \\ ${ }^{4}$ Corresponding author: Tel, 82-42-860-4182; \\ Fax, 82-42-860-4593; E-mail, hglee@ kribb.re.kr \\ *These authors contributed equally to this work.
}

Accepted 27 September 2007

Abbreviations: CLSM, confocal laser scan microscopy; NDRG2, $\mathrm{N}$-myc downstream regulated gene 2; pTNM, tumor-node-metastasis; siRNA, small interfering RNA

\begin{abstract}
Although N-myc downstream regulated gene 2 (NDRG2) has been known to be a tumor suppressor gene, the function of this gene has not been elucidated. In the present study, we investigated the expression and function of NDRG2 in human gastric cancer. Among seven gastric cancer and two non-cancer cell lines, only two gastric cancer cell lines, SNU-16 and SNU-620, expressed NDRG2, which was detected in the cytoplasm. Interestingly, NDRG2 was highly expressed in normal gastric tissues, but gastric cancer patients were divided into NDRG2-positive and -negative groups. The survival rate of NDRG2-negative patients was lower than that of NDRG2-positive patients. We confirmed that the loss of NDRG2 expression was a significant and independent prognostic indicator in gastric carcinomas by multivariate analysis. To investigate the role of NDRG2 in gastric cancer cells, we generated a NDRG2-silenced gastric
\end{abstract}

cancer cell line, which stably expresses NDRG2 siRNA. NDRG2-silenced SNU-620 cells exhibited slightly increased proliferation and cisplatin resistance. In addition, inhibition of NDRG2 decreased Fas expression and Fas-mediated cell death. Taken together, these data suggest that inactivation of NDRG2 may elicit resistance against anticancer drug and Fas-mediated cell death. Furthermore, case studies of gastric cancer patients indicate that NDRG2 expression may be involved in tumor progression and overall survival of the patients.

Keywords: antigens, CD95; cell survival; NDRG2 protein, human; RNA, small interfering; stomach neoplasms; tumor suppressor proteins

\section{Introduction}

$\mathrm{N}$-myc downstream regulated gene 2 (NDRG2), a member of a new family of differentiation-related genes, is highly expressed in adult brain, salivary gland, and skeletal muscle (Boulkroun et al., 2002; Qu et al., 2002). This family is comprised of four members, NDRG1-4, and the expression pattern of these genes is differs during development $(\mathrm{Qu}$ et al., 2002). Human NDRG2 is located at chromosome 14q11.2, includes 16 exons and 15 introns, and encodes a $41 \mathrm{kDa}$ protein. Two isoforms of NDRG2 have been described previously, one of which contains an insertion of $42 \mathrm{bp}$ in the mRNA because of alternative splicing, which results in a protein containing 14 additional amino acids (Boulkroun et al., 2002; Mitchelmore et al., 2004). The biological significance of these isoforms is currently unknown.

NDRG2 has been implicated in cell growth (Deng et al., 2003), differentiation (Choi et al., 2003), and apoptosis (Zhou et al., 2001). It has also been reported that NDRG2 is rapidly responsive to mineralocorticoid stimuli in the kidney (Boulkroun et al., 2002). NDRG2 contains several phosphorylation sites at the C-terminus and its phosphorylation is mediated through insulin-stimulated AKT activation (Burchfield et al., 2004). NDRG2 phosphorylation involves Thr330, Ser332 and Thr348 in skeletal muscle cells (Murray et al., 2004), and Thr334 in rat hippocampus tissue (Chen et al., 
2007). Most recently, it has been shown that NDRG2 is also down-regulated by Myc via transcriptional repression and interact with MSP58, a 58-kDa microspherule protein (Zhang et al., 2006, 2007).

It has been proposed that NDRG2 is a candidate of tumor suppressor gene, and its expression is low level or not detected in various tumors and tumor cell lines (Qu et al., 2002; Deng et al., 2003; Lusis et al., 2005). Liu et al. (2007) revealed that the mechanisms of NDRG2 gene down-regulation in cancer are promoter methylation, mutation, and genomic deletion of NDRG2. Recently, the 14q11.2 chromosome, which contains PARP2, APEX1, and NDRG2 genes was screened for chromosomal imbalances in gastrointestinal stromal tumors by the array-based comparative genomic hybridization (Assamaki et al., 2007). These results support that NDRG2 inactivation is important in the development and progression of gastrointestinal stromal tumor, but the functional role of NDRG2 inactivation in cancer remains unclear.

In this study, we examined the expression of NDRG2 in several gastric cancer cell lines and gastric cancer tissues. To determine the relationship between NDRG2 expression and patient survival, 286 surgically resected cases of gastric cancer were compared. The patient's overall survival, pTNM (Tumor-Node-Metastasis) stages, and histopathologic classification were analyzed. In addition, we generated an NDRG2-silenced stable cell line using retroviral vector-mediated siRNA knock-down technique and investigated cell death induced by chemotherapy, radiotherapy, or Fasligation.

\section{Materials and Methods}

\section{Reagents for cell culture and antibodies}

All cultures were performed in RPMI 1640 medium (Sigma, St. Louis, MO) supplemented with Lglutamine $(2 \mathrm{mM})$, penicillin $(100 \mathrm{U} / \mathrm{ml})$, streptomycin $(100 \mu \mathrm{g} / \mathrm{ml})$, HEPES $(10 \mathrm{mM})$, and $10 \%$ FBS (Gibco BRL, Grand Island, NY). The antibody to human Fas $(\mathrm{CH} 11)$ was purchased from Upstate Biotechnology (Waltham, MA).

\section{Preparation of NDRG2 antibody}

NDRG2 monoclonal antibody was generated using recombinant protein consisting of amino acids 150-357 of NDRG2 (NM_201541). In brief, recombinant NDRG2-C protein extraction and purification were performed according to the protocol for the QIAGEN QIAexpressionist. The eluted recombi- nant NDRG2-C protein was mixed with Freund's adjuvant, and the protein/adjuvant complex was injected into BALB/c mice. Spleen cells of mice immunized with recombinant NDRG2-C protein were harvested, and roughly $50-60 \%$ of all cells were placed in culture after fusion. Cell culture supernatants from selected cell lines were tested by ELISA. Among the growing clones that tested positive, the 19C-4 clone (isotype IgG1) was used for further study. Monoclonal antibody was produced in ascites from BALB/c mice injected with 19C-4 cells.

\section{Tissue specimens}

We identified 286 surgically resected cases of gastric cancer during Jan.-Jul. 1995 from the files of the Department of Pathology, Seoul National University College of Medicine (Lee et al., 2001). Age, gender, tumor location, lymphatic invasion, vascular invasion, and pTNM stage were evaluated by reviewing medical charts and pathologic records. Tissue slides were reviewed for histologic classification (according to the WHO classification and Lauren's classification), and clinical outcome was followed from the date of surgery to the date of death or until the end of 2003. Cases lost during follow-up and those that died from any cause other than gastric cancer were regarded as censored data for the survival analysis.

\section{Tissue array methods}

Core tissue samples, $2.0 \mathrm{~mm}$ in diameter, were taken from representative paraffin blocks with gastric cancer and arranged in a new recipient paraffin block, as previously described (Lee et al., 2001). A total of 6 blocks were used for this study, and each block contained 55 cases of gastric cancer plus three non-neoplastic gastric mucosa samples from body, antrum, and intestinal metaplasia. Because of the excellent agreement between staining results obtained from different intratumoral areas of gastric carcinomas, one core was sampled per case. An adequate case was defined as one with tumor occupying more than $10 \%$ of the core area. Four- $\mu \mathrm{m}$-thick slices were cut from each tissue array block, deparaffinized and then rehydrated.

\section{Immunohistochemistry}

Immunohistochemical staining for NDRG2 was performed with an anti-NDRG2 monoclonal antibody using the labeled streptavidin-biotin method after microwave antigen retrieval. Briefly, the for- 
malin-fixed, paraffin-embedded, $4 \mu \mathrm{m}$-thick sections were dewaxed in xylene, rehydrated through graded alcohol, and placed in an endogenous peroxide block for $15 \mathrm{~min}$. Sections were then washed in water before antigen retrieval, placed in a citrate buffer, and microwaved for $10 \mathrm{~min}$. Diluted anti-NDRG2 monoclonal antibody was then applied, and antibody binding was detected using an avidin-biotin-peroxidase complex kit (Vextor Laboratories, Burlingame, CA) using diaminobenzidine tetrahydrochloride solution (Biogenex, San Ramon, CA).

\section{Construction and transfection of pSUPER-Retro/NDRG2 siRNA in SNU-620 cells}

For generating NDRG2 siRNA vectors, the annealed oligonucleotides containing NDRG2 siRNA oligonucleotides, 5'-CCCAACCTGGATAACATTG3 ', were ligated into pSUPER-retro (Oligoengine) that had been digested with Bg/ll and Hindlll. For stable expression of siRNAs in SNU-620 cells, retroviruses were produced by transfection of 293T packaging cells with the corresponding pSUPERRetro vector, and after $48 \mathrm{~h}$, the virus-containing culture supernatants were used to infect SNU-620 cells. The cells were then selected for 2 weeks in the presence of puromycin $(10 \mu \mathrm{g} / \mathrm{ml})$. Cells were plated in 96-well plates ( 0.5 cell/well), and expanded in the presence of puromycin. NDRG2silenced SNU-620 cell clones were confirmed by Northern blot and Western blot for further investigation.

\section{Northern blot analysis}

Total RNA was extracted from the cultured cells with the acid guanidinium thiocyanate-phenolchloroform extraction method (Chomczynski and Mackey, 1995). Northern blot analysis was performed according to a previously described method (Choi et al., 2003). The NDRG2 probe was prepared from the RT-PCR product using a specific primer set; 5'-ATGGCGGAGCTGCAGG-3' and 3'TCAACAGGAGACCTCCAT-5'.

\section{Western blot analysis}

Cells were homogenized on ice in Pro-PREP ${ }^{\mathrm{TM}}$ protein extraction solution (iNtRon Biotechnology, Seongnam, Korea) containing protease inhibitor; 1 mM PMSF, 1 mM EDTA, $1 \mu \mathrm{M}$ pepstatin A, $1 \mu \mathrm{M}$ leupeptin and $0.1 \mu \mathrm{M}$ aprotinin. After $30 \mathrm{~min}$ on ice, the extracts were centrifuged $(13,000 \times g)$ for $10 \mathrm{~min}$ at $4^{\circ} \mathrm{C}$ and the supernatants were recovered. The protein concentration was measured
(Bio-Rad, Hercules, CA) and approximately $50 \mu \mathrm{g}$ of each extract was loaded for $12 \%$ SDS-PAGE gel, and was then transferred from the gel onto a PVDF membrane (Amersham Biosciences, Little Chalfont, UK). The nonspecific Ab binding sites on the membrane were blocked by incubation of the membrane in PBS $(\mathrm{pH} 7.0)$ containing $0.1 \%$ Tween 20 and $4 \%$ nonfat dry milk for $1 \mathrm{~h}$ at room temperature. The membrane was washed in PBS containing $0.1 \%$ Tween 20 and incubated overnight at $4{ }^{\circ} \mathrm{C}$ with NDRG2 antibody. After washing for $1 \mathrm{~h}$, the membrane was incubated with HRP-conjugated secondary antibody (Sigma) for $1 \mathrm{~h}$ at room temperature. The resulting blot was visualized by ECL-Plus Western detection reagents (Amersham Biosciences).

$\mathbf{A}$

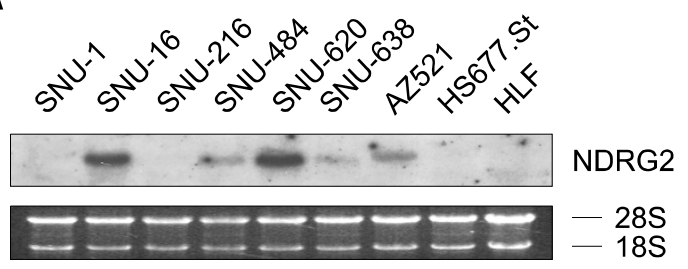

B

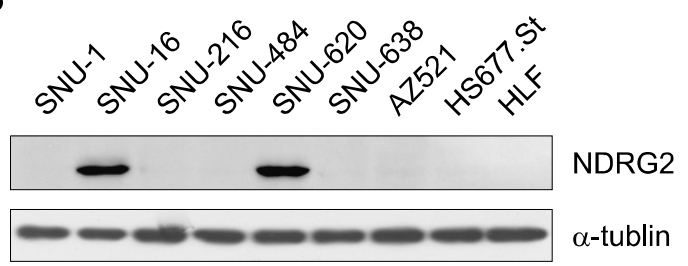

C

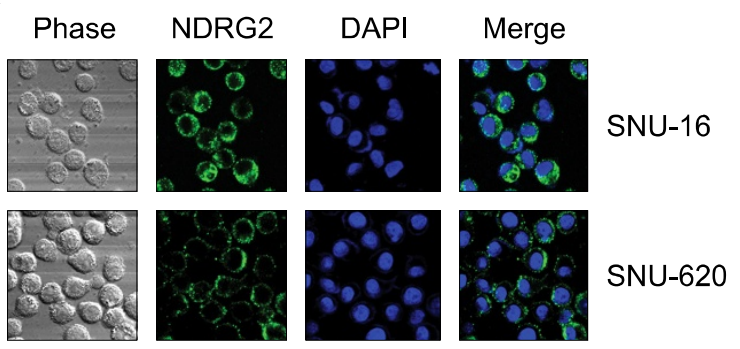

Figure 1. NDRG2 protein expression in human gastric tumor cell lines. (A) Total RNAs were isolated from gastric tumor cell lines, and NDRG2 mRNA was detected using Northern blot analysis. (B) Cell lysates were prepared from human gastric tumor cell lines, and NDRG2 protein expression was determined by Western blot analysis using an anti-NDRG2 monoclonal antibody. (C) Analysis of the cellular distribution of NDRG2 in SNU-16 and SNU-620 gastric tumor cell lines by CLSM. Cells were stained with an NDRG2 monoclonal antibody and DAPI for nuclear staining. 


\section{Proliferation assay}

Actively growing SNU-620-mock and NDRG2silenced SNU-620 cells were plated into 96-well round-bottom plates at a density of $1 \times 10^{4}$ cells per well, and cell proliferation during the last $18 \mathrm{~h}$ of the culture days was quantified by measuring the thymidine uptake of cells incubated with $1 \mu \mathrm{Ci}$ [methyl- ${ }^{3} \mathrm{H}$ ]thymidine (Amersham Pharmacia, Piscataway, NJ). Cells were harvested onto glass fiber filters, and radioactivity was measured using a scintillation counter. Results are presented as mean cpm of cultures performed in triplicate.

\section{Flow cytometric analysis of apoptosis}

For measurement of Fas-mediated cell death, cells were seeded into 6 -well plates at a density of $2 \times$ $10^{6} \mathrm{cell} / \mathrm{ml}$, and stimulating antibody was added. After Fas stimulation, cells were harvested, washed twice with cold PBS, and analyzed for cell death. Apoptosis assessment was performed using FITC-conjugated annexin $\mathrm{V}$ antibody (BD PharMingen, San Diego, CA) and propidium iodide (PI; Sigma), according to the manufacturer's recommendations. The proportion of apoptotic cells in the prepared cells was determined by flow cytometric analysis using FACSCalibur (Becton Dickinson, Mountain View, CA), and data were analyzed using CellQuest software (Becton Dickinson).

\section{Confocal laser scan microscopy (CLSM)}

Gastric cancer cell lines, SNU-16 and SNU-620, were grown on 12-mm diameter glass coverslips coated with poly-L-lysine in 12-well plates. Cells were then rinsed three times in cold PBS, and fixed with $4 \%$ paraformaldehyde for $20 \mathrm{~min}$ at room temperature. After washing with PBS, cells were permeabilized with $0.1 \%$ Triton X-100/PBS for 10 min, and blocking was completed with $1 \%$ BSA (Sigma) in PBS for $30 \mathrm{~min}$ at room temperature. Cells were incubated with a mouse anti-NDRG2 monoclonal antibody, followed by incubation with an Alexa Fluor ${ }^{\circledR}$ 488-conjugated goat anti-mouse IgG antibody, and the nuclei were stained with DAPI. Cells were mounted onto cover glasses with Vectashield mounting medium, and the slides were kept in darkness prior to examination. Confocal images were obtained using a Zeiss LSM 510 META Laser Scanning Microscope (Carl Zeiss, Jena, Germany).

\section{Statistical analyses}

The Chi-square test was used to examine the correlation between NDRG2 expression and clinicopathologic factors. Survival curves were plotted using the Kaplan-Meier product-limit method, and differences between survival curves were tested using the log-rank test. Multivariate survival analysis was performed using the Cox proportional hazards model. Results were considered statistically significant when $P$ values were less than
A
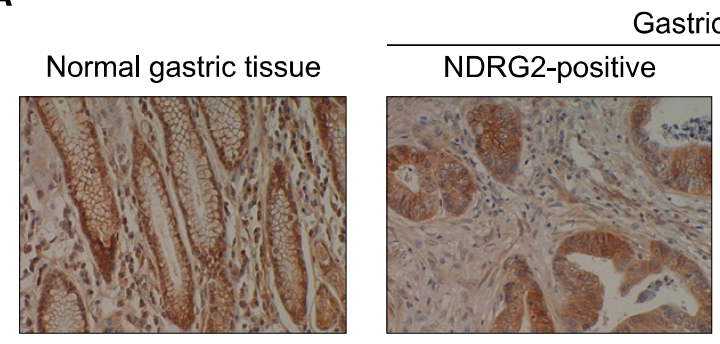

Gastric cancer

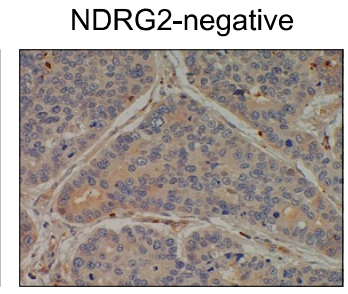

B
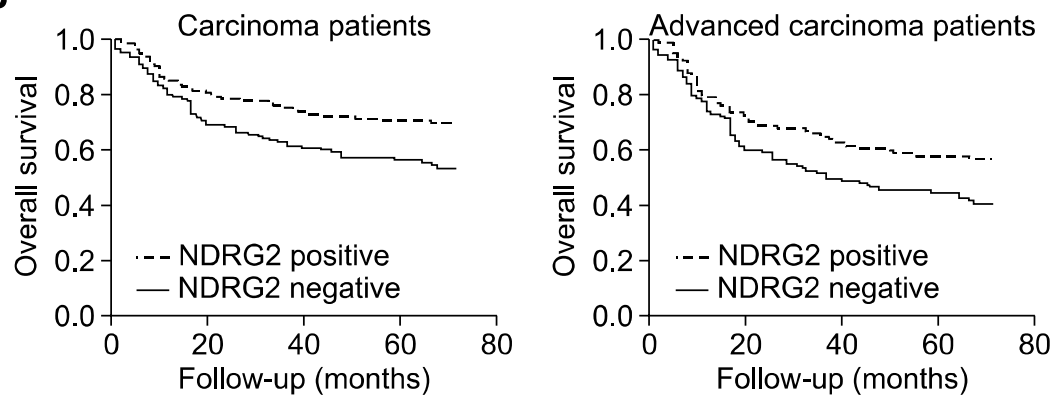

Figure 2. NDRG2 expression in gastric cancer patients. (A) NDRG2 expression was analyzed in non-neoplastic gastric tissues and cancers using immunohistochemical staining with an NDRG2 monoclonal antibody $(\times 200)$. (B) Survival curves were calculated with 281 patients (203 advanced carcinomas and 78 early carcinomas) using the Kaplan-Meier method. These curves show that NDRG2 negative cancers are associated with a worse prognosis $(P<0.001)$. 
0.05 . All statistical analyses were conducted using SPSS Ver. 12.0 (SPSS, Chicago, IL).

\section{Results}

\section{NDRG2 expression in gastric cancer cell lines}

In order to study NDRG2 expression in gastric cancer, we first examined the expression of NDRG2 transcript and protein in 7 different individual human gastric carcinoma cell lines and 2 normal fibroblast cell lines. Interestingly, NDRG2 was strongly expressed in two of seven carcinoma cell lines (SNU-16 and -620), but not in the other

Table 1. Comparison of NDRG2-positive and NDRG2-negative gastric carcinomas.

\begin{tabular}{|c|c|c|c|}
\hline & $\begin{array}{l}\text { NDRG2- } \\
\text { positive } \\
\text { carcinomas } \\
(n=135)\end{array}$ & $\begin{array}{c}\text { NDRG2- } \\
\text { negative } \\
\text { carcinomas } \\
(n=151)\end{array}$ & $P$-value \\
\hline Age (years) & $57.0 \pm 12.6$ & $51.9 \pm 13.3$ & 0.001 \\
\hline Sex & & & 0.103 (NS) \\
\hline Male & 98 & 96 & \\
\hline Female & 37 & 55 & \\
\hline Location & & & 0.039 \\
\hline Antrum & 64 & 90 & \\
\hline Body and cardia & 71 & 61 & \\
\hline WHO classification & & & $0.000^{*}$ \\
\hline Well differentiated & 20 & 4 & \\
\hline Moderately differentiated & 47 & 30 & \\
\hline Poorly differentiated & 44 & 78 & \\
\hline Mucinous & 5 & 11 & \\
\hline Signet ring & 19 & 28 & \\
\hline Lauren classification & & & $0.000^{*}$ \\
\hline Intestinal & 70 & 34 & \\
\hline Diffuse & 53 & 99 & \\
\hline Mixed & 12 & 18 & \\
\hline LN metastasis & & & 0.115 (NS) \\
\hline Absent & 55 & 48 & \\
\hline Present & 80 & 103 & \\
\hline pTNM stage & & & 0.012 \\
\hline 1 & 64 & 52 & \\
\hline$\|$ & 32 & 27 & \\
\hline III & 22 & 45 & \\
\hline IV & 17 & 27 & \\
\hline Lymphatic invasion & & & 0.680 (NS) \\
\hline Negative & 96 & 104 & \\
\hline Positive & 39 & 47 & \\
\hline Vascular invasion & & & 0.988 (NS) \\
\hline Negative & 126 & 141 & \\
\hline Positive & 9 & 10 & \\
\hline
\end{tabular}

${ }^{*} P<0.05 ;$ NS, not significant. gastric carcinoma cell lines or normal fibroblast cell lines (Figure $1 \mathrm{~A}$ and $\mathrm{B}$ ). CLSM analysis showed that NDRG2 expression was mostly localized in the cytoplasm of SNU-16 and -620 cell lines (Figure $1 \mathrm{C})$, consistent with other reports of a cytosolic localization (Qu et al., 2002).

\section{Expression of NDRG2 in gastric cancer tissue and and survival analysis}

We observed that NDRG2 was positively stained in the cytoplasm of non-neoplastic gastric tissues. The gastric cancer cells showed diverse staining result in their cytoplasm. No staining or faint staining was regarded as negative, and weak to distinct staining was counted as positively-stained tumor cells. For statistic analysis, the cases were categorized as NDRG2 positive expression when more than $10 \%$ of cancer cells were positivelystained. Among the 286 gastric cancer cases, 151 cases showed complete loss of NDRG2 expression and 135 cases were positively stained (Figure $2 \mathrm{~A})$. Therefore, we reviewed medical charts and pathologic records of these NDRG2-positive or -negative gastric cancer patients. During the follow-up period, 108 of the 281 gastric cancer patients (38.4\%) had died (68 from the NDRG2 negative group and 40 from the NDRG2 positive group). The survival rate of patients without NDRG2 staining, as determined by the log-rank test, was lower than those showing NDRG2 positive staining $(P=0.008)$ (Figure $2 \mathrm{~B})$. Among 281 gastric cancer patients, 203 cases were advanced carcinoma and 78 cases were early carcinoma. The prognosis of early carcinoma was excellent in both the NDRG2-negative and

Table 2. Multivariate analysis of predictive factors for survival.

\begin{tabular}{lcc}
\hline Prognostic factors & Hazards ratio $(95 \% \mathrm{Cl})$ & $P$ value \\
\hline $\begin{array}{l}\text { Sex } \\
\text { Male vs. female }\end{array}$ & $0.84(0.54-1.30)$ & $\mathrm{NS}$ \\
Lauren classification & $0.83(0.45-1.53)$ & $\mathrm{NS}$ \\
$\quad$ Diffuse vs. intestinal & $0.83(0.47-1.47)$ & $\mathrm{NS}$ \\
$\quad$ Mixed vs. intestinal & $13.59(4.28-43.20)$ & $<0.001$ \\
$\begin{array}{l}\text { Depth of tumor } \\
\text { Advanced vs. early }\end{array}$ & $2.44(1.62-3.68)$ & $<0.001$ \\
Lymphatic invasion \\
$\quad \begin{array}{l}\text { Present vs. absent } \\
\text { Distant metastasis } \\
\quad \text { Present vs. absent }\end{array}$ & $2.91(1.59-5.32)$ & 0.001 \\
NDRG2 & $1.63(1.08-2.45)$ & 0.02 \\
$\quad$ Negative vs. positive & & \\
\hline NS, not significant. &
\end{tabular}

NS, not significant. 
NDRG2-positive group $(5.5 \%$ and $2.4 \%$ of the patients died respectively, significance of difference, $P>0.1$ ). The survival rate of the NDRG2negative was also lower than those of NDRG2positive group for advanced carcinoma cases $(P=$ $0.03)$. NDRG2 expression was strongly associated with histological subtype of gastric carcinoma; loss of expression is less frequent in intestinal type and well- to moderately-differentiated types (Table 1). It may suggest that the alteration of NDRG2 dependent on the carcinogenic pathways. By multivariate analysis, the loss of NDRG2 expression was a significant and independent prognostic indicator in gastric carcinomas (Table 2). NDRG2-negative gastric carcinomas were more likely to be an advanced pTNM stage $(P=0.012)$, but there were no significant differences in lymph node metastasis, lymphatic invasion, or vascular invasion. In addition, the Cox proportional hazards model showed that higher NDRG2 expression was associated with decreased overall mortality (Table 2).
A
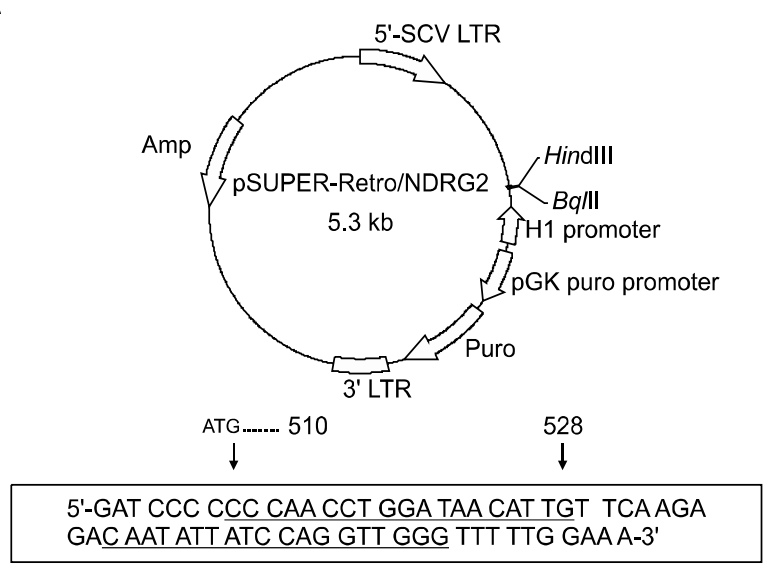

5'-AGC TTT TCC AAA AAC CCAACC TGG ATAACA TTG TCT CTT GAA CAA TAT TAT CCA GGT TGG GGG G-3'

D

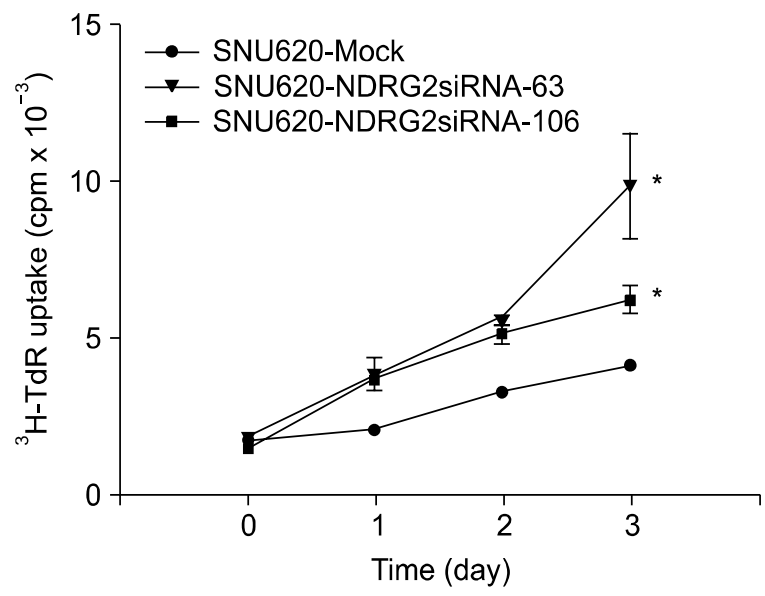

B

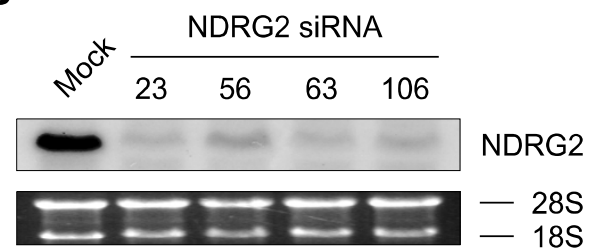

C

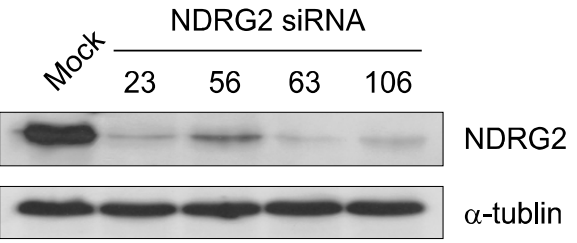

E

Day 1

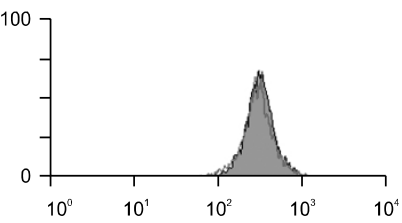

Day 2

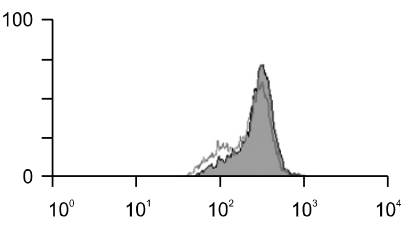

Day 3

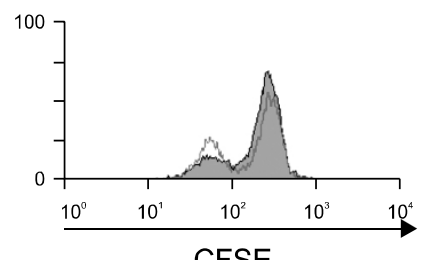

Figure 3. NDRG2-silenced SNU-620 cells exhibit increased proliferation. (A) NDRG2 expression in SNU-620 cell was inhibited using retroviral vector-mediated siRNA knock-down as shown in a schematic diagram of the pSUPER-Retro vector encoding NDRG2 siRNA. (B-C) After selection of NDRG2-silenced SNU-620 cells with puromycin, several clones were selected using Northern blot (B) and Western blot analysis (C). (D-E) Cell proliferation was measured by the incorporation of radioactive thymidine using a scintillation counter for the last $16 \mathrm{~h}\left(\mathrm{D}\right.$, Student's $t$ test, ${ }^{*} P<0.005$ compared with SNU-620-mock transfectant) and by dilution of CellTrace ${ }^{\text {TM }}$ CFSE (E, filled histogram, SNU-620 mock transfectant; open histogram, NDRG2-silenced SNU-620 cells). 
A

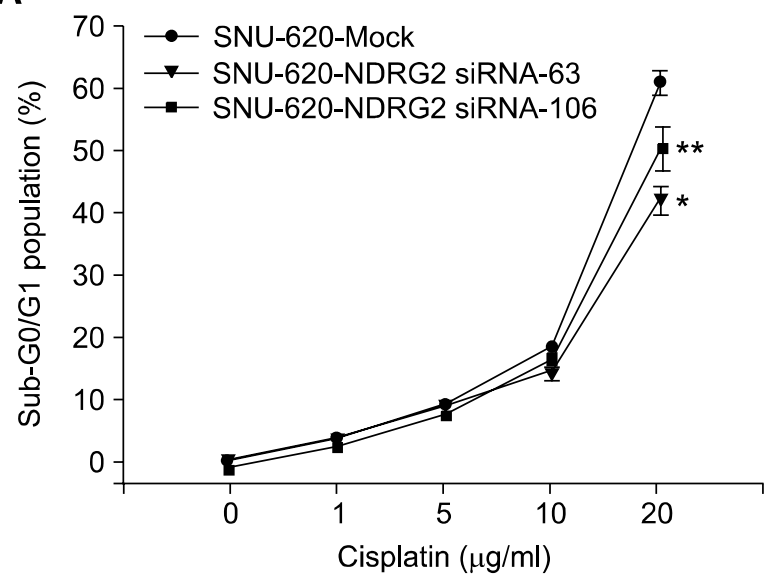

B

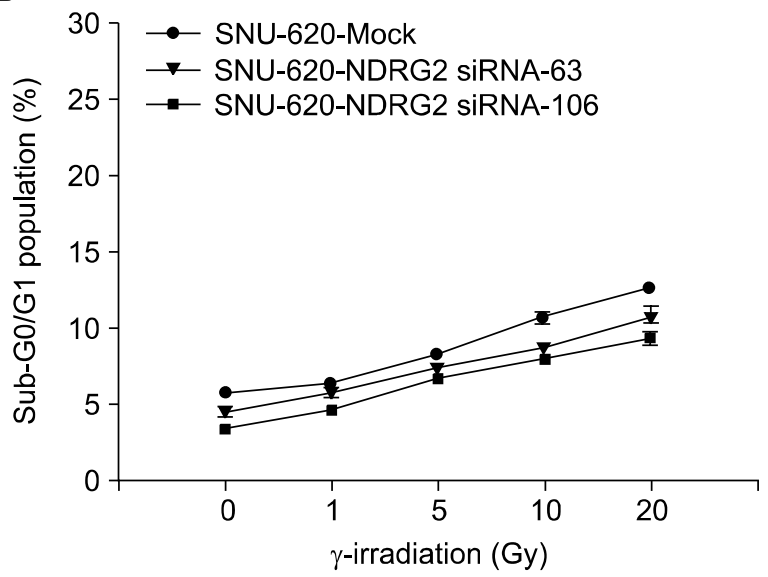

Figure 4. Induction of cell death in NDRG2-silenced SNU-620 cell by chemotherapy or radiation. NDRG2-silenced SNU-620 cells were treated with cisplatin at the indicated different concentrations for $24 \mathrm{~h}(\mathrm{~A})$, or cells were incubated for $24 \mathrm{~h}$ after treatment with the indicated dosages of $\gamma$-irradiation (B). Cells were fixed with $70 \%$ ethanol, stained with propidium iodide, and then subjected to flow cytometric analysis. The percentage of sub-G0/G1 phase cells was determined based on the DNA content histograms (Student's $t$ test, ${ }^{*} P<0.005,{ }^{* *} P<0.05$ compared with SNU-620-mock transfectant).

\section{Generation of a NDRG2-silenced gastric cancer cell line}

To investigate the function of NDRG2 in gastric cancer cell survival, the pSUPER-retro vector encoding NDRG2 siRNA was transfected into SNU-620 cells using a retrovirus (Figure $3 A$ ). NDRG2-silenced SNU-620 clones (number 23, 56, 63 and 106) showed significantly reduced NDRG2 transcript and protein levels (Figure 3B and $\mathrm{C}$ ). Because NDRG2 has been found to be linked to the inhibition of cell proliferation (Deng et al., 2003), we analyzed the cell proliferation rate in NDRG2-silenced SNU-620 cells. NDRG2-silenced SNU-620 cells showed a slightly increased cell proliferation rate (Figure 3D and E), with no significant difference in morphology (data not shown).

To examine whether NDRG2 influences cell death, cell death was induced in NDRG2-silenced SUN-620 cells using a chemotherapy or $\gamma$-irradiation and measured by flow cytometry. Cisplatininduced cell death was slightly decreased in NDRG2-silenced SNU-620 cells compared with SNU-620-mock transfectant (Figure 4A). However, $\gamma$-irradiation did not significantly increased cell death at $20 \mathrm{~Gy}$ irradiation, so no differences in cell death could not been observed (Figure 4B). Taken together, these results indicated that inactivation of NDRG2 may increase resistance against chemotherapy such as cisplatin.

\section{Effect of NDRG2 on Fas expression and Fas-mediated cell death}

Gene profiling in NDRG2-silenced SNU-620 cells using a human $10 \mathrm{~K}$ cDNA chip showed that several genes related to cell proliferation and death were differentially expressed (data not shown). To investigate cell death in relation to NDRG2 expression, we first analyzed the expression of the death receptor, CD95/Fas (Apo-1), in NDRG2-silenced SNU-620 cells. Interestingly, Fas expression was slightly decreased in NDRG2-silenced SNU-620 cells, although its expression was not highly detected in SNU-620 cells (Figure 5A). In accordance with this result, Fas expression was increased in NDRG2-overespressing U937 cells (data not shown). Next, we examined the ability to induce apoptosis by anti-Fas antibody in NDRG2silenced SNU-620 cells. Annexin V labeling was significantly decreased in NDRG2-silenced SNU620 cells in the flow cytometric analysis (Figure $5 B)$. In addition, annexin $V$ and propidium iodide double positive cells were decreased with time in NDRG2-silenced SNU-620 cells (Figure 5C). Therefore, consistently with the survival rates in gastric cancer patients, silencing of NDRG2 increased resistance to both anti-cancer drugs and Fas-mediated apoptosis.

\section{Discussion}

Gastric cancer is the second most common cause of cancer-related mortality in the world. Once common in western societies but now much less common, gastric cancer is still amongst the most common cancers in some other countries, especially in Japan and Korea (Stephens, 2001). In this paper we compared the expression of 
A

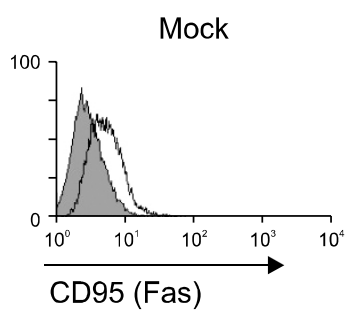

B

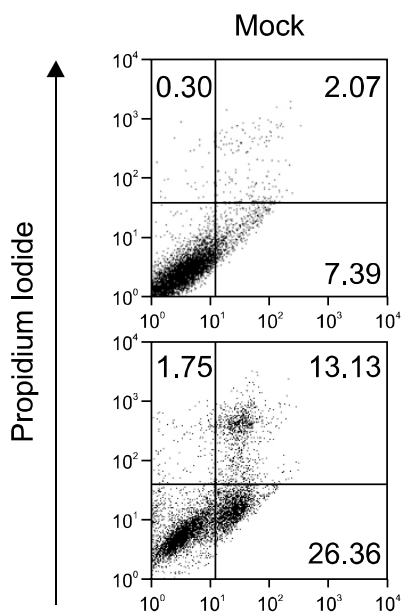

NDRG2 siRNA-63

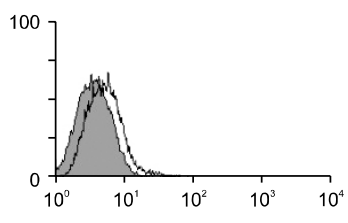

NDRG2 siRNA-106

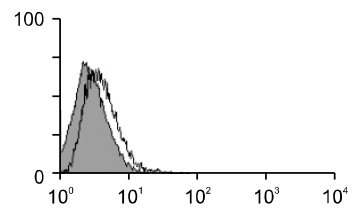

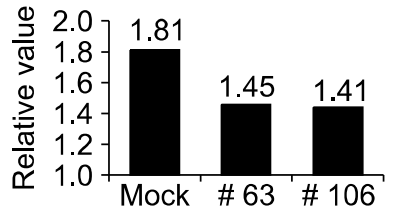

NDRG2 siRNA-106

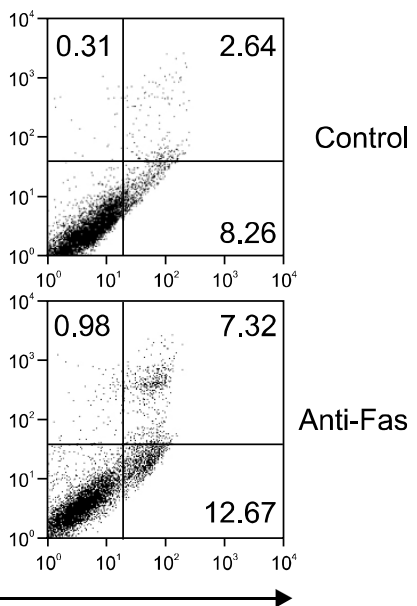

Annexin-V FITC

\section{C}

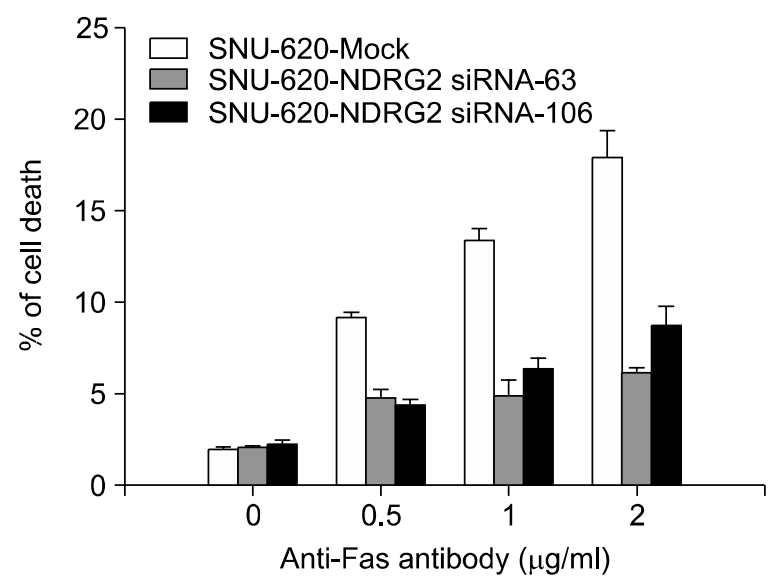

NDRG2 in gastric cancer patients with tumor progression and survival rates. Inactivation of tumor suppressor genes is important during the development of cancer, and NDRG2 is a candidate of tumor suppressor genes (Lusis et al., 2005; Assamaki et al., 2007; Liu et al., 2007). It was previously reported that down-regulation of NDRG2 occurs in glioblastoma, pancreatic cancer, liver cancer, and clinically aggressive meningioma (Deng

Figure 5. Fas-mediated cell death was decreased in NDRG2-silenced SNU-620 cells. (A) The cell surface expression of Fas was analyzed by flow cytometry (filled histogram, antibody control; open histogram, staining with anti-Fas antibody). The relative values of Fas expression were calculated as follows; MFI (mean fluorescence intensity) of Fas/ MFI of anti-mouse Ig FITC. (B) NDRG2- silenced SNU-620 cells were treated with an agonistic Fas antibody $(1 \mu \mathrm{g} / \mathrm{ml})$ for $24 \mathrm{~h}$, and cell death was analyzed by staining with annexin $\mathrm{V}$ and propidium iodide. (C) After treatment with anti-Fas antibody in a does-dependent manner for $24 \mathrm{~h}$, the percentages of annexin $\mathrm{V}$ and $\mathrm{Pl}$-positive cells were compared between NDRG2-silenced SNU-620 cells and mock transfectant.

et al., 2003; Hu et al., 2004; Lusis et al., 2005). Among 7 human gastric carcinoma cell lines tested, only SNU-16 and -620 cells expressed NDRG2 transcript and protein. Furthermore, we analyzed NDRG2 expression in gastric cancer tissues, and our data indicated that $47 \%$ of gastric cancer cases showed positive staining for NDRG2. The survival rate of patients without NDRG2 staining was lower than those showing NDRG2- positive staining. In 
addition, loss of NDRG2 expression was associated with the carcinogenesis and progression of gastric carcinoma in multivariate analysis.

The era of chemotherapy was ushered in the introduction of polyfunctional alkylating agents in the early 1940s. Since then, a wide array of antitumor drugs has become available, most of them affecting proliferating cells. Contemporary chemotherapies for advanced gastric cancer, usually containing 5-fluorouracil and cisplatin, demonstrate response rates in the $20-40 \%$ range, with median survival between 6 and 12 months (Meyerhardt and Fuchs, 2002). It was previously reported that cisplatin resistance correlates with decreased levels of pyruvate kinase M2 (PK-M2) and activity in human gastric carcinoma cell lines (Yoo et al., 2004). However, our results indicated that cisplatininduced cell death slightly decreased in NDRG2silenced SNU-620 cells. Because NDRG2 possesses potential phosphorylation sites (Murray et al., 2004; Chen et al., 2007) and involved signaling cascades (Burchfield et al., 2004), NDRG2 inhibition may disrupt cisplatin-mediated signaling.

In our study, inhibition of NDRG2 expression in the gastric cancer cell line, SNU-620, decreased Fas-mediated cell death via down-regulation of Fas expression. Death receptors are members of the tumor necrosis factor receptor gene superfamily, which consists of more than 20 proteins with a broad range of biological functions, including the regulation of cell death and survival (Debatin and Krammer, 2004). The best-characterized apoptosis-inducing death receptors are Fas (Apo-1), TNF receptor (TNFR) and TNF-related apoptosisinducing ligand receptor (TRAIL-R). Interestingly our results showed that Fas expression was downregulated in NDRG2-silenced SNU-620 cells, and Fas-mediated cell death was also inhibited in these cells. It was recently reported that NDRG2 interacted with a cell cycle-dependent transcription factor MSP58, and this interaction between NDRG2 and MSP58 played an important role in controlling cell cycle (Zhang et al., 2007). NDRG2 may modulate a physical state of cell through interaction with another protein, because we found several genes in NDRG2-silenced SNU-620 cells using DNA chip array. Therefore, further study requires how NDRG2 modulated Fas expression and other genes. Although it has been proposed that the expression of Fas ligand (FasL) in tumors may play an important role in immune escape, apoptosis of tumor cells was induced by Fasmediated apoptotic signals through binding to the FasL of NK cells. NK cells kill virus-infected and tumor cells via several direct or indirect pathways (Liu et al., 1995; Kashii et al., 1999; Lieberman,
2003), including perforin/granzyme- and death receptor (FASL or TRAIL)-mediated cell death (Screpanti et al., 2005). We also observed that NDRG2-silenced SNU-620 cells were less susceptible than SNU-620-mock cells to death induced by activated human NK cells (data not shown).

Collectively, our results demonstrate that inactivation of NDRG2 in gastric cancer is involved in carcinogenesis and tumor progression, and that the decreased survival rate in NDRG2-negative gastric cancer patients may be linked to resistance against anti-cancer drugs or Fas-mediated apoptosis.

\section{Acknowledgements}

This work was supported by FG07-12-01 of the 21C Frontier Functional Human Genome Project from the Ministry of Science and Technology in Korea and by KRIBB Research Initiative Program. J.-S. Lim was partly supported by a grant R11-2005-017-03001 from the Research Center for Women's Diseases of KOSEF.

\section{References}

Assamaki R, Sarlomo-Rikala M, Lopez-Guerrero JA, Lasota J, Andersson LC, Llombart-Bosch A, Miettinen M, Knuutila $\mathrm{S}$. Array comparative genomic hybridization analysis of chromosomal imbalances and their target genes in gastrointestinal stromal tumors. Genes chromosomes \& cancer 2007;46:564-76

Boulkroun S, Fay M, Zennaro MC, Escoubet B, Jaisser F, Blot-Chabaud M, Farman N, Courtois-Coutry N. Characterization of rat NDRG2 (N-Myc downstream regulated gene 2), a novel early mineralocorticoid-specific induced gene. J Biol Chem 2002;277:31506-15

Burchfield JG, Lennard AJ, Narasimhan S, Hughes WE, Wasinger VC, Corthals GL, Okuda T, Kondoh H, Biden TJ, Schmitz-Peiffer, C. Akt mediates insulin-stimulated phosphorylation of Ndrg2: evidence for cross-talk with protein kinase C theta. J Biol Chem 2004;279:18623-32

Chen WQ, Hoeger H, Diao WF, Pollak A, Lubec G. Mass Spectrometrical Characterization of NDRG2 Protein (Nmyc-Downstream Regulated Gene 2) and Description of Two Novel Phosphorylation Sites. Neurochem Res 2007

Choi SC, Kim KD, Kim JT, Kim JW, Yoon DY, Choe YK, Chang YS, Paik SG, Lim JS. Expression and regulation of NDRG2 ( $\mathrm{N}$-myc downstream regulated gene 2) during the differentiation of dendritic cells. FEBS Lett 2003;553:413-8

Chomczynski P, Mackey K. Substitution of chloroform by bromo-chloropropane in the single-step method of RNA isolation. Anal Biochem 1995;225:163-4

Debatin KM, Krammer, PH. Death receptors in chemotherapy and cancer. Oncogene 2004;23:2950-66 
Deng Y, Yao L, Chau L, Ng SS, Peng Y, Liu X, Au WS, Wang J, Li F, Ji S, Han H, Nie X, Li Q, Kung HF, Leung SY, Lin MC. N-Myc downstream-regulated gene 2 (NDRG2) inhibits glioblastoma cell proliferation. Int J Cancer 2003;106:342-7

Hu XL, Liu XP, Lin SX, Deng YC, Liu N, Li X, Yao LB. NDRG2 expression and mutation in human liver and pancreatic cancers. World J Gastroenterol 2004;10:3518-21

Kashii Y, Giorda R, Herberman RB, Whiteside TL, Vujanovic NL. Constitutive expression and role of the TNF family ligands in apoptotic killing of tumor cells by human NK cells. J Immunol 1999;163:5358-66

Lee HS, Lee HK, Kim HS, Yang HK, Kim YI, Kim WH. MUC1, MUC2, MUC5AC, and MUC6 expressions in gastric carcinomas: their roles as prognostic indicators. Cancer 2001;92: 1427-34

Lieberman J. The ABCs of granule-mediated cytotoxicity: new weapons in the arsenal. Nat Rev Immunol 2003;3: 361-70

Liu CC, Walsh CM, Eto N, Clark WR, Young, JD. Morphologic and functional characterization of perforin-deficient lymphokine-activated killer cells. J Immunol 1995;155:602-8

Liu N, Wang L, Liu X, Yang Q, Zhang J, Zhang W, Wu Y, Shen L, Zhang Y, Yang A, Han H, Zhang J, Yao L. Promoter methylation, mutation, and genomic deletion are involved in the decreased NDRG2 expression levels in several cancer cell lines. Biochem Biophys Res Commun 2007;358:164-9

Lusis EA, Watson MA, Chicoine MR, Lyman M, Roerig P, Reifenberger G, Gutmann DH, Perry A. Integrative genomic analysis identifies NDRG2 as a candidate tumor suppressor gene frequently inactivated in clinically aggressive meningioma. Cancer Res 2005;65:7121-6

Meyerhardt JA, Fuchs CS. Chemotherapy options for gastric cancer. Semin Radiat Oncol 2002;12:176-86

Mitchelmore C, Buchmann-Moller S, Rask L, West MJ, Troncoso JC, Jensen NA. NDRG2: a novel Alzheimer's disease associated protein. Neurobiol Dis 2004;16:48-58

Murray JT, Campbell DG, Morrice N, Auld GC, Shpiro N, Marquez R, Peggie M, Bain J, Bloomberg GB, Grahammer F, Lang F, Wulff P, Kuhl D, Cohen P. Exploitation of KESTREL to identify NDRG family members as physiological substrates for SGK1 and GSK3. Biochem J 2004;384:477-88

Qu X, Zhai Y, Wei H, Zhang C, Xing G, Yu Y, He F. Characterization and expression of three novel differentiation-related genes belong to the human NDRG gene family. Mol Cell Biochem 2002;229:35-44

Screpanti V, Wallin RP, Grandien A, Ljunggren HG. Impact of FASL-induced apoptosis in the elimination of tumor cells by NK cells. Mol Immunol 2005;42:495-9

Stephens FO. Induction chemotherapy: to downgrade aggressive cancers to improve curability by surgery and/or radiotherapy. Eur J Surg Oncol 2001;27:672-88

Yoo BC, Ku JL, Hong SH, Shin YK, Park SY, Kim HK, Park JG. Decreased pyruvate kinase M2 activity linked to cisplatin resistance in human gastric carcinoma cell lines. Int $\mathrm{J}$ Cancer 2004;108:532-9

Zhang J, Li F, Liu X, Shen L, Liu J, Su J, Zhang W, Deng Y, Wang L, Liu N, Han W, Zhang J, Ji S, Yang A, Han H, Yao L. The repression of human differentiation-related gene NDRG2 expression by Myc via Miz-1-dependent interaction with the NDRG2 core promoter. J Biol Chem 2006;281: 39159-68

Zhang J, Liu J, Li X, Li F, Wang L, Zhang J, Liu X, Shen L, Liu $\mathrm{N}$, Deng Y, Yang A, Han H, Zhao M, Yao L. The physical and functional interaction of NDRG2 with MSP58 in cells. Biochem Biophys Res Commun 2007;352:6-11

Zhou RH, Kokame K, Tsukamoto Y, Yutani C, Kato H, Miyata T. Characterization of the human NDRG gene family: a newly identified member, NDRG4, is specifically expressed in brain and heart. Genomics 2001;73:86-9 